\title{
A Reconfigurable Polarization-Frequency Supershape Patch Antenna with Enhanced Bandwidth
}

\author{
Anastasios Koutinos@, Georgia Xanthopoulou, George Kyriacou and Michael Chryssomallis * \\ Democritus University of Thrace, Electrical \& Computer Engineering Department, 67100 Xanthi, Greece; \\ akoutino@ee.duth.gr (A.K.); georxant8@ee.duth.gr (G.X.); gkyriac@ee.duth.gr (G.K.) \\ * Correspondence: mchrysso@ee.duth.gr
}

Received: 1 May 2020; Accepted: 15 July 2020; Published: 18 July 2020

\begin{abstract}
In this article a reconfigurable antenna for WLAN/WiMAX applications is presented. A super-shape radiator of an ellipsis shape is used to achieve wider intrinsic bandwidth compared to the classical rectangular patch antenna, while the dimensions remain comparable. The proposed antenna is fed at two points exciting both horizontal and vertical polarization but in different operating frequencies. To achieve wider bandwidth, as a whole but also for each polarization, the symmetrical feeding points for each excitation are also employed with a proper feeding network. PIN diodes are also used in the feeding network to provide the option of narrower bandwidth. The antenna substrate is Rogers RO4003C with dielectric constant $\varepsilon_{r}=3.55$ and dissipation losses $\tan \delta=0.0027$ with height $\mathrm{h}=1.524 \mathrm{~mm}$. The antenna operates in the range of $2.3 \mathrm{GHz}$ to $2.55 \mathrm{GHz}$ but, using the proposed procedure, it can be designed for different frequency ranges.
\end{abstract}

Keywords: wideband reconfigurable antennas; new feeding techniques; dual polarization; multifrequency antennas; supershape

\section{Introduction}

Modern day wireless communication systems have radiation requirements that can be satisfied using different antennas. In order to achieve a more compact structure and if possible a single device, reconfigurable antennas are one of the solutions that are able to meet these expectations [1]. Frequency, polarization and radiation patterns are some of the antenna properties that would be required to be reconfigurable if a multifunction device would be designed. From the characteristics mentioned above, the radiation pattern is of minor importance because in general it can be achieved through phased arrays. This is achieved in [2] with the implementation of a reconfigurable feeding network, and in [3], through the use of a reconfigurable frequency selective surface (FSS). A different approach to have radiation pattern reconfigurability is to actually design an antenna, which has an omnidirectional pattern consisting of several identical endfire sectors pointing to opposite directions. In this way, by activating a different part of the antenna, a corresponding pattern is enabled, resulting in pattern-reconfigurable properties. This is properly explained in [4], where the omnidirectional pattern contains two identical patterns, while in [5], the same principle is studied but with four brackets for the antenna and four patterns as well. Another important characteristic of reconfigurable antennas is the possibility to operate on different frequencies. This is presented in [6], where a wideband antenna with a monopole topology is studied. Between the radiating element and the feeding port, a reconfigurable bandpass filter (BPF) is placed which has the ability to shift its central frequency and so the whole structure can alter its resonant frequency. Actually, this antenna can operate to wideband or narrowband states with the narrowband one offering several adjacent frequencies one at a time. An alternate method for frequency reconfigurability is shown in [7], where through the activation of different combinations of PIN diodes, adjacent frequencies can be also utilized. The PIN diodes can 
also be applied to achieve frequency altering in case of multiband behavior as explained in [8]. Here the only striking diversity is that while the general resonant properties remains the same, each case of PIN diode configuration result to better matching for different frequencies of the same bandwidth.

In a similar way as described in [6] wideband antennas can be designed. The main principle is that one can utilize an UWB antenna and with the proper modifications, to exclude some frequency bands and thus a wideband behavior can be achieved. This is presented in [9], where the UWB antenna is a Bow-Tie in monopole topology. Using a number of switches three states can be studied, each with its own central frequency and bandwidth (BW) as well. The same principle is exhibited in [10] with the only difference being that the distinct states are able to cover the entire BW with one of them being redundant (OFF-ON). Another example of this procedure is presented in [11] where two "nearly" monopoles, mainly because the ground plane is not entirely absent for them, are used. Here their ground plane consists of a reconfigurable branched structure with which some bands are forfeited as seen by the gain and efficiency figures. The major drawback of the monopole structures is the low efficiency due to their omnidirectional pattern and specifically the existence of a back-lobe.

Finally, for an antenna to become reconfigurable is in its polarization. In [12], two monopoles are used using switches to render each one active or not. Each monopole has linear polarization (LP) and they are fed by the same port. Since they are placed vertically, three possible linear (horizontal, vertical and their combination aka diagonal) polarizations are observed. A similar idea is presented in [13], but here, a slot array antenna is used with each port having LP and thus dual LP is achieved. The concept of dual LP is studied in [14], employing two vertical dipoles each with its own LP as well. Another approximation on the polarization issue is the exploration of right hand circular polarization or left hand circular polarization (RHCP and LHCP) which is carried out in [15]. Here using two switches, the current distribution direction on the radiating element can be controlled and thus RHCP or LHCP can be realized but with the same radiation pattern. Related to [15] but with more complexity is the antenna proposed in [16] where RHCP or LHCP can be realized on demand in a fairly wide BW.

The issue we try to address is to have an antenna with different polarizations which is operating within a fair BW but also with ease of fabrication as well as keeping the antenna as compact as possible. Most of the approaches from literature have either a large number of PIN diodes or bigger dimensions. Therefore, at this paper an ellipsis Supershape Patch Antenna (SPA) is proposed. A SPA has the same bandwidth compared to a rectangular operating at the same central frequency but utilizes circular polarization and so common radiation properties can be achieved through the entire operation bandwidth. Our work can be directly compared to that of [17], where a rectangular patch, with its intrinsic narrow BW and linear polarization, was designed and one can see that a similar design procedure is carried out, resulting to significantly narrower bandwidth for the circular polarization.

\section{Antenna Design}

\subsection{Dual Fed SPA}

In order to utilize both resonances (modes $\mathrm{TM}_{10}$ and $\mathrm{TM}_{10}$ ) for greater bandwidth, our initial approach will start using a rectangular patch. The major drawback however is that different modes radiate with horizontal, and vertical polarization, respectively, thereby making the entire bandwidth unusable as a whole. To counter this issue, an ellipsis SPA is chosen mainly because Supershape geometries can be used as antenna structures with similar characteristics as studied in [18]. The main feature of Supershape antennas is the circular polarization even when they are fed at a single point. The dielectric substrate was chosen to be Rogers RO4003C with dielectric constant $\varepsilon_{\mathrm{r}}=3.55$, dissipation losses $\tan \delta=0.0027$ and thickness $h=1.0524 \mathrm{~mm}$. The geometry shape of the ellipsis is a result of Equation (1), known as Supershape formula, taken from [19]. Following up, the ellipsis is scaled by a factor of 1.271 for the vertical dimension. The scaling is done in order the resonant frequency of the vertical side to shift appropriately and come closer to the one of the horizontal side. After the 
scaling the geometry looks like a circle but this is because the two axes $\left(\mathrm{r}_{1}\right.$ and $\left.\mathrm{r}_{2}\right)$ are almost but not exactly equal.

$$
r(\varphi)=\left[\left|\frac{1}{a} \cos \left(\frac{m}{4} \varphi\right)\right|^{n_{2}}+\left|\frac{1}{b} \sin \left(\frac{m}{4} \varphi\right)\right|^{n_{3}}\right]^{-n_{1}}
$$

In Equation (1), terms $a$ and $b$ represent the horizontal and vertical dimension of the resulting shape. The "contribution" of each term is determined by $n_{2}$ and $n_{3}$ while $n_{1}$ defines the sharpness of the supershape corners. As stated in [19], "For $n_{1}=n_{2}=n_{3}=2$ and $m=4$ an ellipse is obtained. A circle is obtained when additionally, $a=b^{\prime \prime}$. The Equation (1) has no units because the supershape dimensions can be assigned to any (i.e. $\mathrm{mm}$ or $\mathrm{cm}$ etc). To achieve dual band behavior, two feeding points are chosen for the proposed SPA, one on each of the two axes. The geometry of the antenna, with the positions of feeding points, is shown in Figure 1.

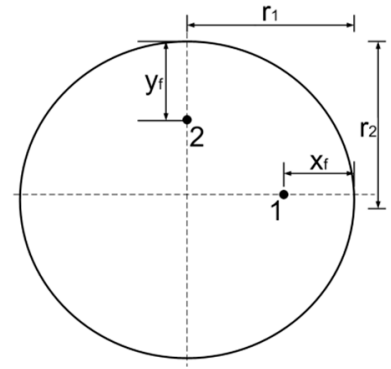

(a)

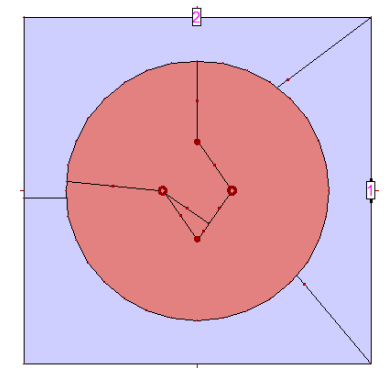

(b)

Figure 1. Supershape Patch antenna geometry (a) Dimension design and (b) IE3D design.

The positions of feeding points \#1 and \#2 are chosen to have different impedance in order to spare space for the placement of the feeding network. Due to the geometry of the antenna, the horizontal side has smaller input impedance value than the vertical one on the edge. As such, if both feeding points were chosen to have $Z_{o}=50 \mathrm{Ohm}$, the feeding ports distance would be small enough and coupling phenomena would occur between them with the result of poor radiation. The parameters of the antenna are given in Table 1 as well as the different port impedances.

Table 1. Values of Supershape patch parameters.

\begin{tabular}{cccc}
\hline Parameter & Value & Parameter & Value \\
\hline $\mathrm{m}$ & 1 & $\mathrm{r}_{1}$ & $19 \mathrm{~mm}$ \\
$\mathrm{n}_{1}$ & 0.5 & $\mathrm{r}_{2}$ & $18.71 \mathrm{~mm}$ \\
$\mathrm{n}_{2}$ & 5 & $\mathrm{x}_{\mathrm{f}}$ & $14 \mathrm{~mm}$ \\
$\mathrm{n}_{3}$ & 5 & $\mathrm{y}_{\mathrm{f}}$ & $11.05 \mathrm{~mm}$ \\
$\mathrm{a}$ & 0.8902 & $\mathrm{Z}_{01}$ & $50 \mathrm{Ohm}$ \\
$\mathrm{b}$ & 0.8902 & $\mathrm{Z}_{02}$ & $130 \mathrm{Ohm}$ \\
\hline
\end{tabular}

The simulations have been carried out using the Method of Moments (MoM) implemented by the Zeland IE3D simulator. For the characterization of the antenna, the S-parameters are used which provide information about the well matching of the SPA. As expected, each feeding point excites a single resonance while the coupling between the two ports is insignificant (below $-25 \mathrm{~dB}$ ) as presented in Figure 2. 


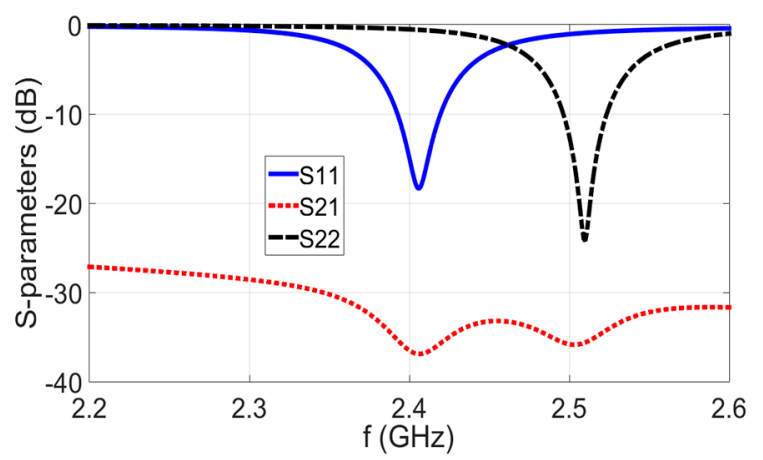

Figure 2. S-Parameters of supershape patch antenna.

As seen in Figure 2 each resonance is well matched (below $-10 \mathrm{~dB}$ ). In Table 2 all the important frequencies of the SPA are given along with the bandwidth of each resonance. The two resonances are chosen with no common frequencies because the bandwidth of each resonance is to be enhanced and so a considerable wider bandwidth is formed.

Table 2. Important frequencies of the SPA.

\begin{tabular}{ccc}
\hline & Resonance $\mathbf{1}\left(\mathbf{S}_{\mathbf{1 1}}\right)$ & Resonance 2 $\left.\mathbf{( S}_{\mathbf{2 2}}\right)$ \\
\hline $\mathrm{f}_{\mathrm{L}}(\mathrm{GHz})$ & 2.4006 & 2.5033 \\
$\mathrm{f}_{\mathrm{H}}(\mathrm{GHz})$ & 2.4366 & 2.5314 \\
$\mathrm{f}_{\mathrm{C}}(\mathrm{GHz})$ & 2.4186 & 2.5173 \\
$\mathrm{BW}(\mathrm{MHz})$ & 36 & 28.1 \\
$\mathrm{BW}(\%)$ & 1.48 & 1.11 \\
\hline
\end{tabular}

\subsection{Bandwidth Enhancement of Dual Fed SPA}

The SPA is modified to increase its bandwidth. The bandwidth enhancement is implemented using a matching feeding network as described in [20] and in a similar way to the one in [17]. The feeding points 1, 2 and 3, 4 are connected through separate feeding networks for $50 \mathrm{Ohm}$ and $130 \mathrm{Ohm}$ respectively due to lack of space as well as to avoid coupling effects between the ports. The proposed geometry is multilayer having the radiating patch on the top layer, the middle layer serving as ground plane while the feeding network is to be placed on the bottom layer. This can be easily done using different substrates for the patch and the feeding network and glue them together to keep common ground plane afterwards. The different layers of the geometry of the proposed modified SPA are shown in Figure 3 and its dimensions are given in Table 3.

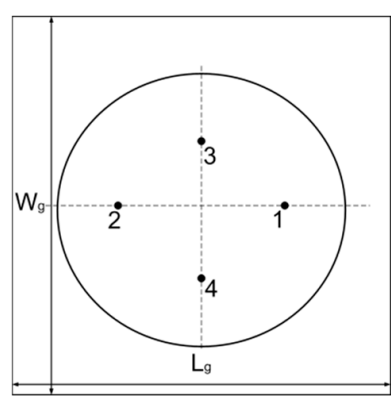

(a)

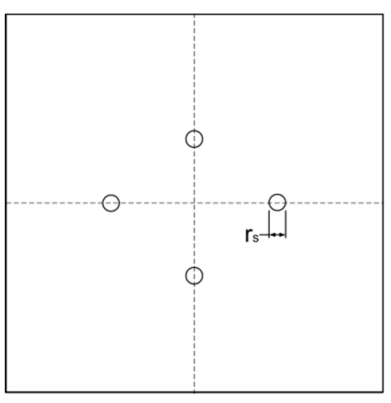

(b)

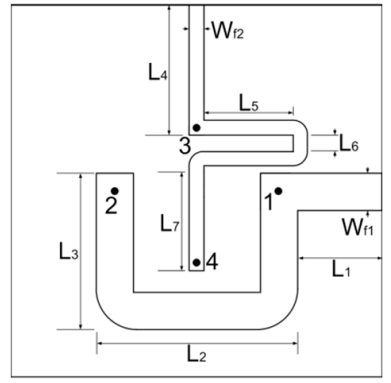

(c)

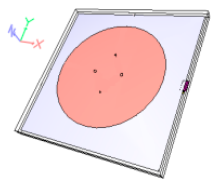

(d)

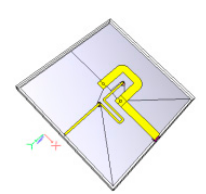

(e)

Figure 3. The three layers of the geometry of the proposed modified SPA, (a) patch (top), (b) ground plane (middle), (c) feeding network (bottom), (d) IE3D top view and (e) IE3D bottom view. 
Table 3. Modified SPA dimensions (all values in $\mathrm{mm}$ ).

\begin{tabular}{cccc}
\hline Parameter & Value & Parameter & Value \\
\hline $\mathrm{Lg}_{\mathrm{g}}$ & 50 & $\mathrm{~L}_{2}$ & 13.5 \\
$\mathrm{~W}_{\mathrm{g}}$ & 50 & $\mathrm{~L}_{3}$ & 15.45 \\
$\mathrm{r}_{\mathrm{s}}$ & 1 & $\mathrm{~L}_{4}$ & 18.4 \\
$\mathrm{~W}_{\mathrm{f} 1}$ & 3.5 & $\mathrm{~L}_{5}$ & 9.9 \\
$\mathrm{~W}_{\mathrm{f} 2}$ & 0.8 & $\mathrm{~L}_{6}$ & 1.8 \\
$\mathrm{~L}_{1}$ & 18.25 & $\mathrm{~L}_{7}$ & 11.8 \\
\hline
\end{tabular}

The size of the proposed antenna is kept the same (ground plane dimensions) but its thickness is doubled because of the second dielectric substrate. The antenna is fed from both ports simultaneously to confirm the bandwidth increase of each resonance but also the bridging of the gap between the two separate resonances, so the S-parameters of the antenna are given in Figure 4.

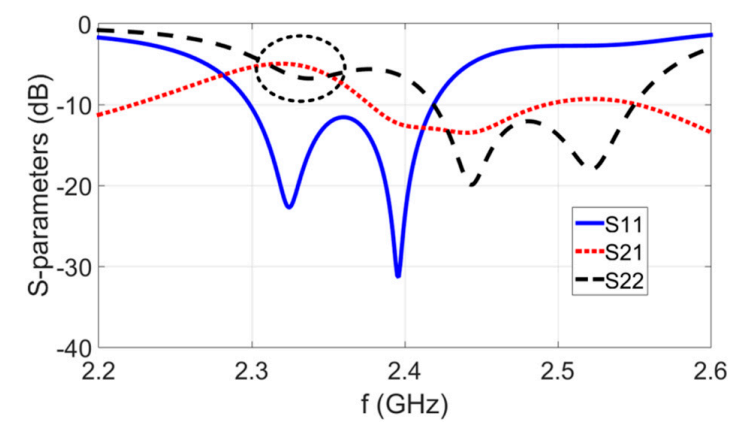

Figure 4. S-Parameters of modified SPA.

As it is observed, there is an issue with the coupling between the two ports because it is not negligible as it is for the SPA (Figure 2). Especially in $2.32 \mathrm{GHz}$ (black circle) $\mathrm{S}_{21}$ has its maximum value $(\approx-5 \mathrm{~dB})$ and as such it is expected to have little to none radiation to that frequency area. This could be countered using a proper matching circuit, which will transform the $Z_{\text {in2 }}=130 \mathrm{Ohm}$ to $50 \mathrm{Ohm}$ while will keep the $Z_{\text {in1 }}=50 \mathrm{Ohm}$ at the same time, as it has been described in [21]. Given that, in Table 4 the frequencies and bandwidth of each resonance are listed.

Table 4. Important frequencies of the SPA.

\begin{tabular}{ccc}
\hline & Resonance $\mathbf{1}\left(\mathbf{S}_{\mathbf{1 1}}\right)$ & Resonance 2 $\mathbf{( S}_{\mathbf{2 2}} \mathbf{)}$ \\
\hline $\mathrm{f}_{\mathrm{L}}(\mathrm{GHz})$ & 2.2985 & 2.4187 \\
$\mathrm{f}_{\mathrm{H}}(\mathrm{GHz})$ & 2.4188 & 2.5501 \\
$\mathrm{f}_{\mathrm{C}}(\mathrm{GHz})$ & 2.3586 & 2.4844 \\
$\mathrm{BW}(\mathrm{MHz})$ & 120.3 & 131.4 \\
$\mathrm{BW}(\%)$ & 5.1 & 5.29 \\
\hline
\end{tabular}

The two resonances are barely overlapping, as shown from the higher frequency of the first resonance and the lower frequency of the second resonance, forming the expected wider bandwidth. The modified SPA is going to be further altered by using PIN diodes in order to achieve the reconfigurable behavior we are looking for.

\section{Reconfigurable SPA}

The use of PIN diodes can give different radiation and matching characteristics leading to the result that modified SPA becomes a reconfigurable antenna. The antenna with the PIN diodes is shown in Figure 5, where the positions of diodes are shown (the blue rectangles), while the other dimensions are the same as before, given in Table 3. Also, the top and bottom views of the fabricated 
prototype are given. The different states of the PIN diodes (ON or OFF) create 4 possible cases to explore, as explained in Table 5.

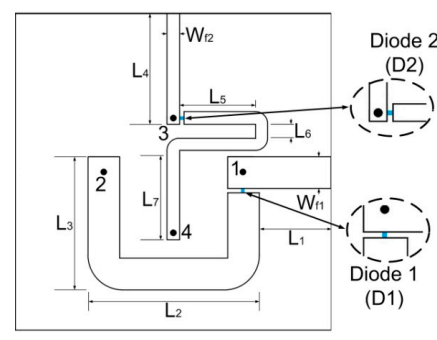

(a)

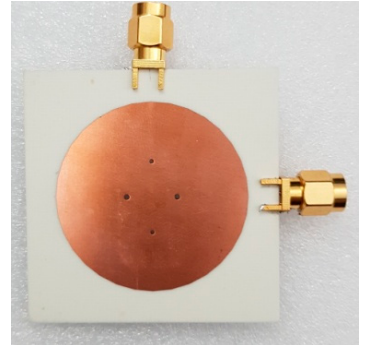

(b)

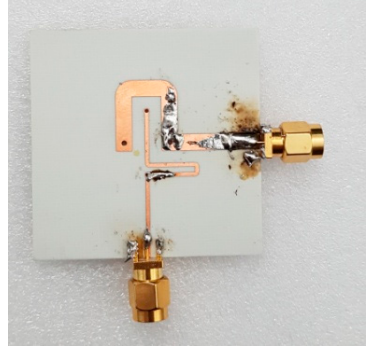

(c)

Figure 5. Geometry of SPA (a) Bottom side of the modified SPA with PIN diodes, (b) Top view of the prototype SPA and (c) Bottom vie of the prototype SPA.

Table 5. Different configurations of PIN diodes.

\begin{tabular}{ccc}
\hline \multirow{2}{*}{ Case } & \multicolumn{2}{c}{ State } \\
\cline { 2 - 3 } & D1 & D2 \\
\hline 1 & Off & Off \\
2 & On & Off \\
3 & Off & On \\
4 & On & On \\
\hline
\end{tabular}

For each of these four cases, a different simulation has been carried out in order to determine its radiation properties. The simulated results of the return losses $\left(\mathrm{S}_{11}\right),\left(\mathrm{S}_{22}\right)$ and the coupling of the two ports $\left(S_{21}\right)$ for each of the cases of Table 5 are given (with the $S_{12}$ not given due to being equal to $\left(S_{21}\right)$ in Figure 6. In Table 6 all the frequencies of each case are shown.

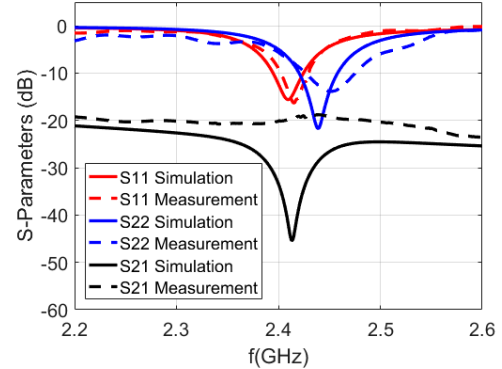

(a)

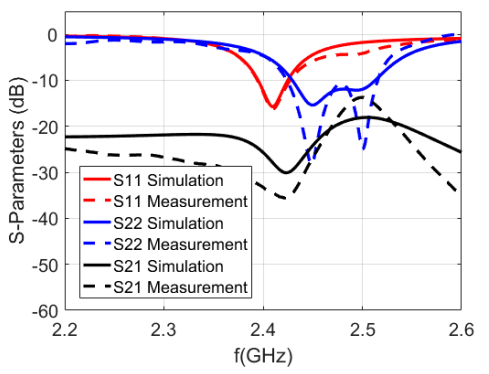

(c)

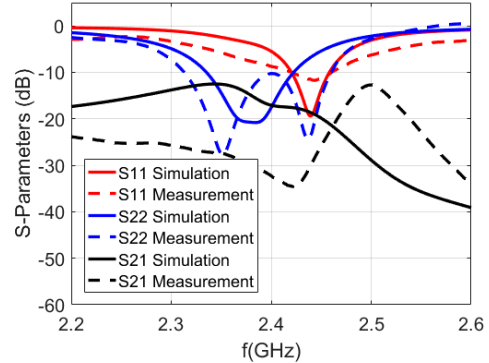

(b)

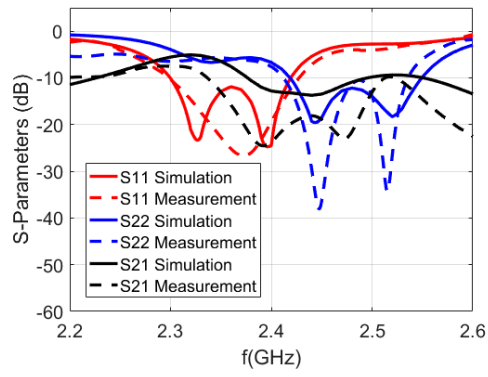

(d)

Figure 6. S-Parameters for each case of Table 5, (a) Case 1, (b) Case 2, (c) Case 3 and (d) Case 4. 
Table 6. Important frequencies of the SPA for the different cases of Table 5.

\begin{tabular}{ccccccc}
\hline & \multicolumn{2}{c}{ Case 1 } & \multicolumn{2}{c}{ Case 2 } & \multicolumn{2}{c}{ Case 3 } \\
\hline & $\begin{array}{c}\text { Resonance 1 } \\
\left(\mathbf{S}_{\mathbf{1 1}}\right)\end{array}$ & $\begin{array}{c}\text { Resonance 2 } \\
\left.\mathbf{( S}_{\mathbf{2 2}}\right)\end{array}$ & $\begin{array}{c}\text { Resonance 1 } \\
\mathbf{( S}_{\mathbf{1 1}} \mathbf{)}\end{array}$ & $\begin{array}{c}\text { Resonance 2 } \\
\mathbf{( S}_{\mathbf{2 2}} \mathbf{)}\end{array}$ & $\begin{array}{c}\text { Resonance 1 } \\
\left(\mathbf{S}_{\mathbf{1 1}} \mathbf{)}\right.\end{array}$ & $\begin{array}{c}\text { Resonance 2 } \\
\left(\mathbf{S}_{\mathbf{2 2}}\right)\end{array}$ \\
\hline $\mathrm{f}_{\mathrm{L}}(\mathrm{GHz})$ & 2.3946 & 2.4205 & 2.3352 & 2.4202 & 2.3949 & 2.4294 \\
$\mathrm{f}_{\mathrm{C}}(\mathrm{GHz})$ & 2.4095 & 2.4393 & 2.3788 & 2.4392 & 2.4098 & 2.4711 \\
$\mathrm{f}_{\mathrm{H}}(\mathrm{GHz})$ & 2.4245 & 2.4582 & 2.4224 & 2.4582 & 2.4248 & 2.5129 \\
$\mathrm{BW}(\mathrm{MHz})$ & 29.9 & 37.7 & 87.2 & 38 & 29.9 & 83.5 \\
$\mathrm{BW}(\%)$ & 1.24 & 1.54 & 3.66 & 1.55 & 1.24 & 3.38 \\
\hline
\end{tabular}

As one can easily see, for the three of the four cases (cases 1, 2 and 3) the coupling between ports is very weak $\left(\mathrm{S}_{21}<-10 \mathrm{~dB}\right)$. Especially in Case 1 and 3, as shown in Figure 6a,c, the coupling is even lower $\left(\mathrm{S}_{21}<-15 \mathrm{~dB}\right)$ and so the two resonances have good radiation for their respected frequency areas. This is also indicative of the fact that each port could be activated separately and so one of the resonances could be excited any time.

Observing the frequency limits of each resonance in Table 6, it is obvious that only for the Case 2 the resonances are actually overlapping $\left(\mathrm{f}_{\mathrm{Hres} 1}<\mathrm{f}_{\mathrm{Lres} 2}\right)$. However, for the other two cases, the frequencies have small deviation and so a whole bandwidth consisting of both resonances can be formed. Having the S-parameters of the structure we have the flexibility of exciting either both ports or one of them depending on our demands for smaller or larger bandwidth. Therefore, for each case the different combinations of port excitations are given in Table 7. The Case 4 is not further explored here due to lack of proper matching.

Table 7. Different configurations for Port 1-Port 2.

\begin{tabular}{ccc}
\hline Case 1 & Case 2 & Case 3 \\
\hline On-Off & On-Off & On-Off \\
Off-On & Off-On & Off-On \\
On-On & On-On & On-On \\
\hline
\end{tabular}

By nature, the supershape patch has circular-elliptical polarization, so to further study and determine this, the radiation patterns for each configuration of Table 7 are given in Figures 7-9 and in each one the left hand circular polarization (LHCP) and right hand circular polarization (RHCP) are shown. Also the E-total is given, depicting the radiation pattern of the antenna in general. 


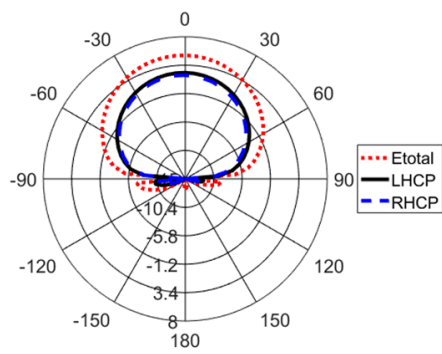

(a)

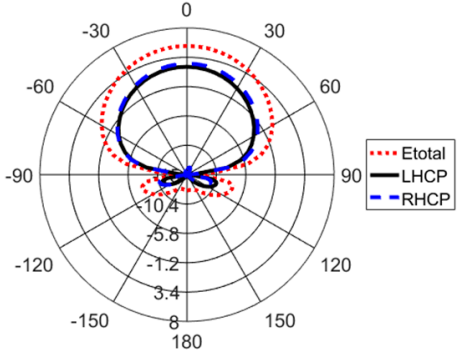

(d)

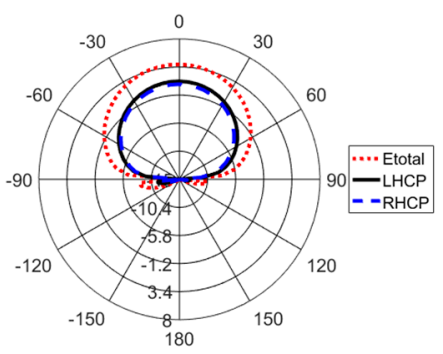

(b)

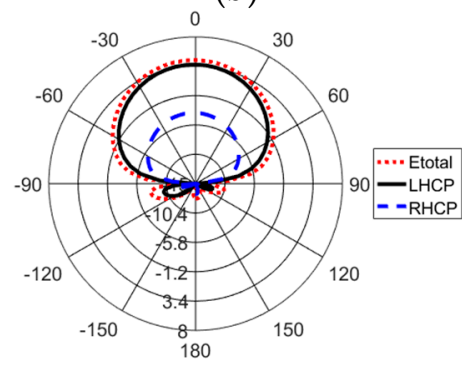

(e)

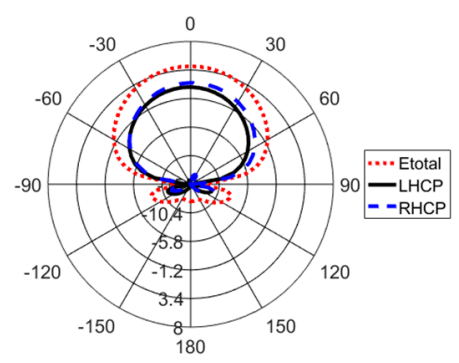

(c)

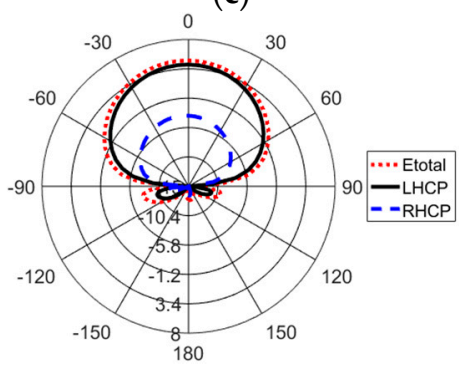

(f)

Figure 7. Radiation patterns for center frequencies of each resonance for Case 1 (a) $f=2.409 \mathrm{GHz}$ for On-Off, (b) $\mathrm{f}=2.439 \mathrm{GHz}$ for On-Off, (c) $\mathrm{f}=2.409 \mathrm{GHz}$ for Off-On, (d) $\mathrm{f}=2.439 \mathrm{GHz}$ for Off-On, (e) $\mathrm{f}=2.409 \mathrm{GHz}$ for On-On and (f) $\mathrm{f}=2.439 \mathrm{GHz}$ for On-On.

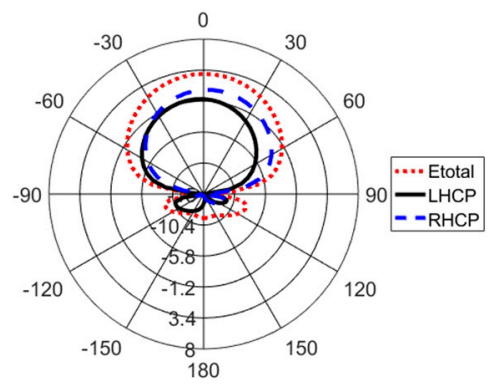

(a)

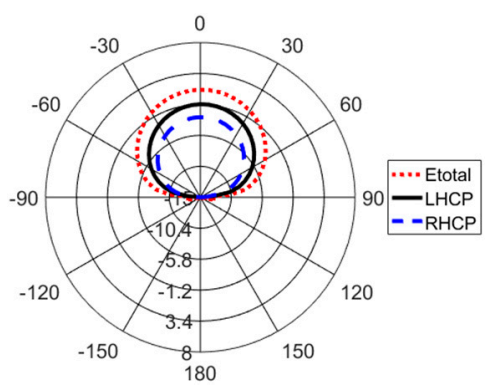

(d)

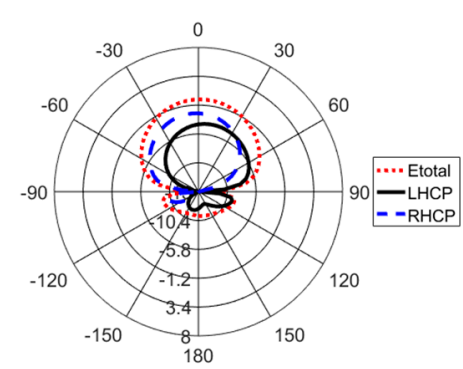

(b)

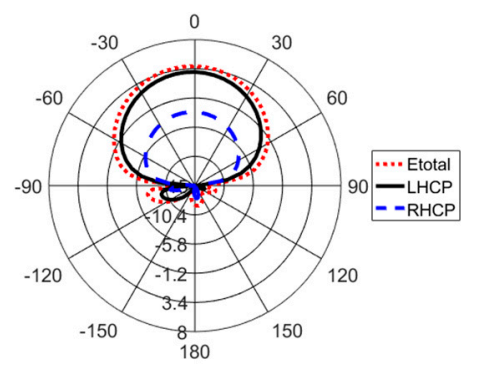

(e)

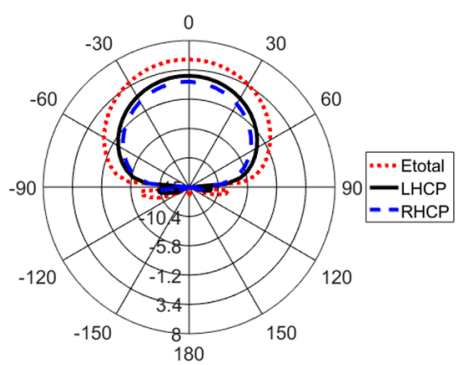

(c)

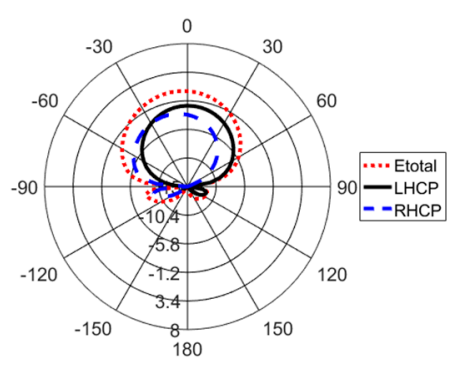

(f)

Figure 8. Radiation patterns for center frequencies of each resonance for Case 2 (a) $\mathrm{f}=2.409 \mathrm{GHz}$ for On-Off, (b) $\mathrm{f}=2.479 \mathrm{GHz}$ for On-Off, (c) $\mathrm{f}=2.409 \mathrm{GHz}$ for Off-On, (d) $\mathrm{f}=2.479 \mathrm{GHz}$ for Off-On, (e) $\mathrm{f}=2.409 \mathrm{GHz}$ for On-On and $(\mathbf{f}) \mathrm{f}=2.479 \mathrm{GHz}$ for On-On. 


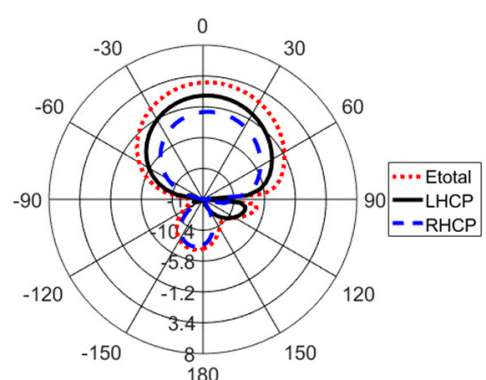

(a)

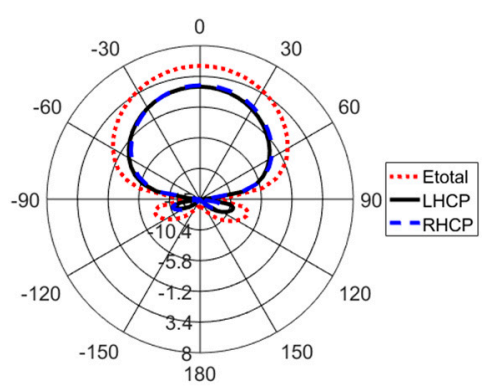

(d)

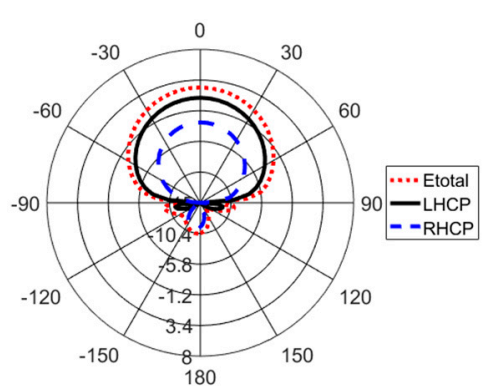

(b)

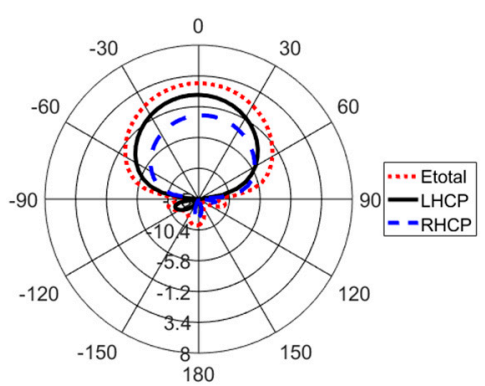

(e)

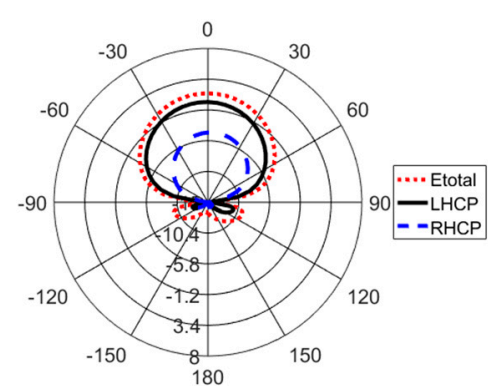

(c)

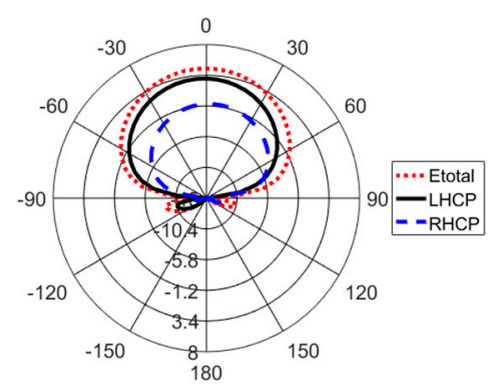

(f)

Figure 9. Radiation patterns for center frequencies of each resonance for Case 3 (a) $\mathrm{f}=2.379 \mathrm{GHz}$ for On-Off, (b) $\mathrm{f}=2.439 \mathrm{GHz}$ for On-Off, (c) $\mathrm{f}=2.379 \mathrm{GHz}$ for Off-On, (d) $\mathrm{f}=2.439 \mathrm{GHz}$ for Off-On, (e) $\mathrm{f}=2.379 \mathrm{GHz}$ for On-On and $(\mathbf{f}) \mathrm{f}=2.439 \mathrm{GHz}$ for On-On.

In Figures 7-9 there are several different polarizations depending on the port configuration. For example, in Figure 7a-d we have LHCP and RHCP but with equal amplitudes. The result is linear polarization because the LHCP negates the one axis of RHCP and vice versa. On the other hand, in Figure 7e-f, since the LHCP is the same as the total E-field, while the RHCP is significantly weaker, we have circular polarization. In the rest of the patterns (Figures 8 and 9), in some circumstances, neither LHCP nor RHCP are equal with the total E-field. This is indicative of a combination of those circular polarizations resulting to elliptical one. To sum up, by exciting different ports, linear or circular - elliptical polarization can be achieved. In fact the exact circular polarization could be a result of different amplitude between feeding ports because the original polarization is elliptical and so we can make use of Left Hand (LH), Right Hand (RH) circular-elliptical or even linear polarization. This can also be seen in Figure 10 where the axial ratio is observed for the different configurations of ports in Case 2 (D1 On and D2 Off). Each port excitation is in the form A, $\theta$ for $A \cdot e^{j \theta}$ (his configuration is selected at random to extract a distinct figure).

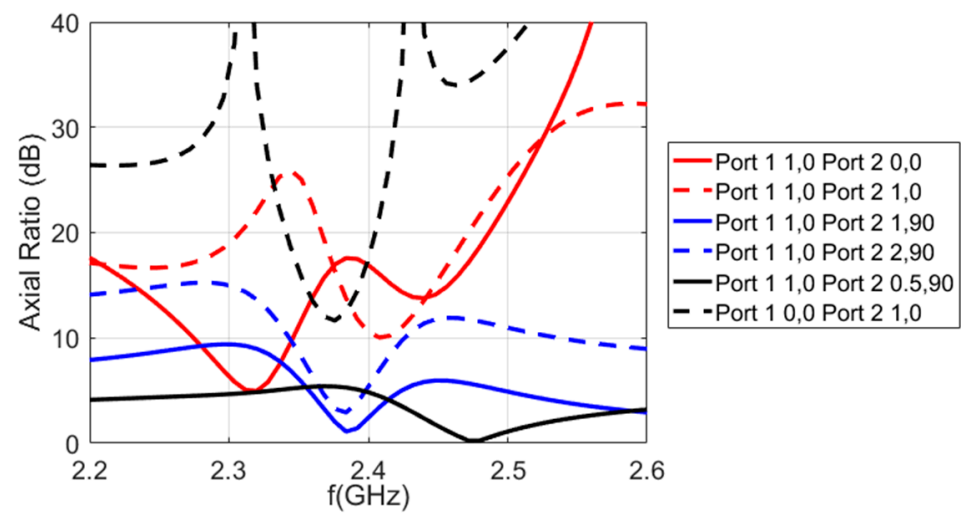

Figure 10. Axial ratio vs. frequency for different excitation signals for Case 2. 
Here we can have all the aforementioned polarization by controlling the amplitude and phase of the excitation of each port. So, by not exciting one of the ports, we can utilize linear polarization while by using a phase difference of $90^{\circ}$ degrees with the proper amplitude ratio we can utilize circular polarization. The gain along with the efficiency of each case is given in Figure 11, where we observe that the Gain ( $\mathrm{dBi}$ ) of the antenna ranges between 3 and $5.5 \mathrm{~dB}$ while the efficiency is above $50 \%$ for the operation BW of each case. The efficiency is reduced compared to a common patch but this is a result of the bandwidth enhancement [22] of each resonance and not of the use of PIN diodes.

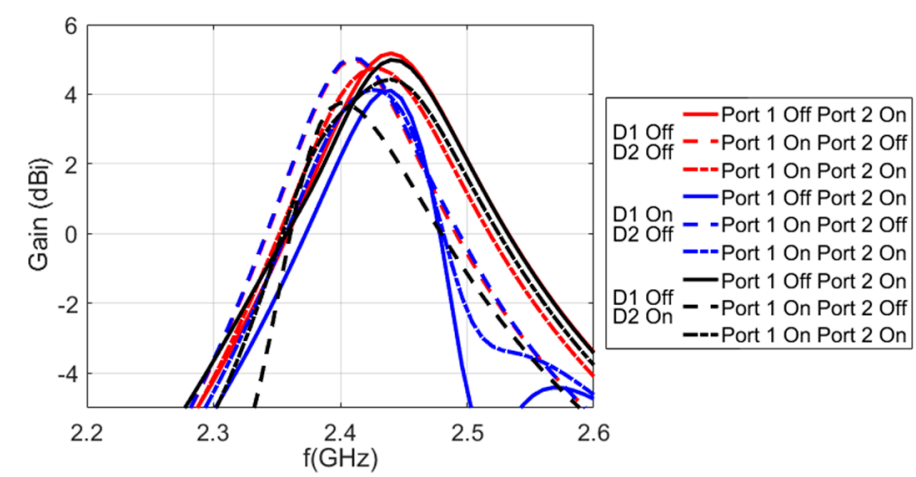

(a)

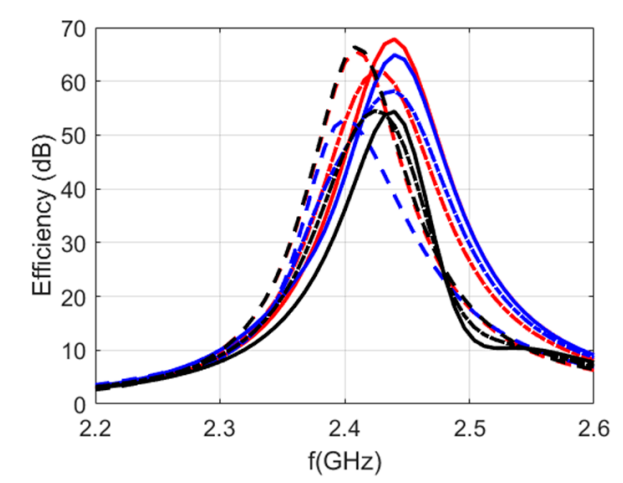

(b)

Figure 11. (a) Gain vs. frequency and (b) Efficiency vs. frequency for each case.

\section{Proper use of Case 4 (Switch 1 on-Switch 2 on)}

The Case 4 of Table 5 have not been thoroughly explored due to significant coupling $\left(\mathrm{S}_{21}\right.$ being above $-10 \mathrm{~dB}$ ) between the two ports. As an effort to utilize the Case 4 configuration, proper matching is necessary using matching circuits after each port. The matching is not realized through some of the techniques of the literature but through an optimization procedure. The goal of the optimization is to match the port 2 to $Z_{\text {in2 }}=50 \mathrm{Ohm}$ while keeping the port 1 to $Z_{\text {in } 1}=50 \mathrm{Ohm}$. We used Optenni Lab to design it [23]. The optimized matching network for both ports as it was produced by Optenni Lab is depicted in Figure 12. The elements T2, T5 and T7 are transfer lines and the rest of them (T1, T3, T4, T6 and T8) are open circuited stubs. The results for the S-parameters after matching are given graphically in Figure 13, and the values of the important frequencies in Table 8, respectively.

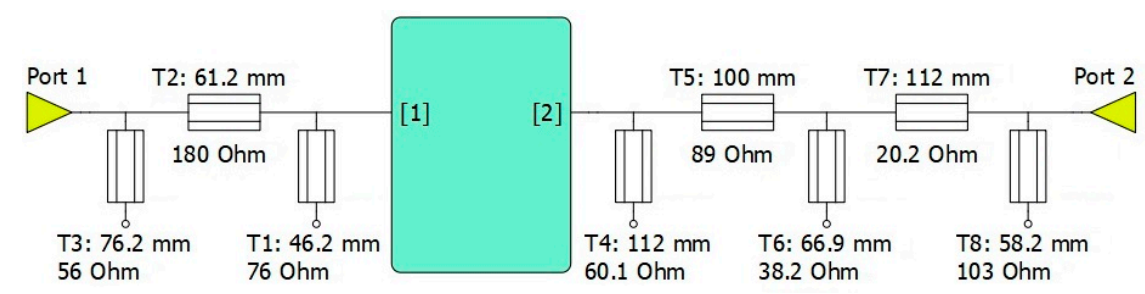

Figure 12. Matching circuits of ports 1 and 2 after optimization. 


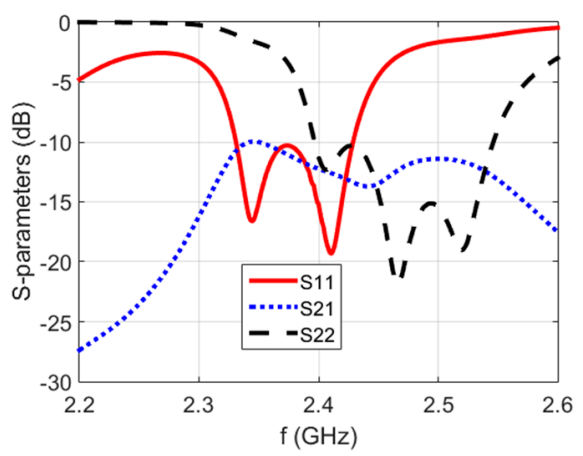

Figure 13. S-parameters of well-matched Case 4 (Switch 1 and 2 On).

Table 8. Important frequencies of the well-matched Case 4.

\begin{tabular}{ccc}
\hline & Resonance $\mathbf{1}\left(\mathbf{S}_{\mathbf{1 1}}\right)$ & Resonance 2 $\mathbf{( S}_{\mathbf{2 2}} \mathbf{)}$ \\
\hline $\mathrm{f}_{\mathrm{L}}(\mathrm{GHz})$ & 2.3309 & 2.3979 \\
$\mathrm{f}_{\mathrm{H}}(\mathrm{GHz})$ & 2.4289 & 2.5469 \\
$\mathrm{f}_{\mathrm{C}}(\mathrm{GHz})$ & 2.3799 & 2.4724 \\
$\mathrm{BW}(\mathrm{MHz})$ & 98 & 149 \\
$\mathrm{BW}(\%)$ & 4.11 & 6.02 \\
\hline
\end{tabular}

\section{Comparison with State of the Art Designs from the Literature}

A comparison of the proposed antenna characteristics to similar designs from the recent literature is summarized in Table 9. It is obvious that the proposed work is able to produce any kind of polarization except the diagonal one, while its dimensions are kept small enough to be able to be attached to a mobile device.

Table 9. Characteristics Comparison of proposed SPA with other works from the literature.

\begin{tabular}{|c|c|c|c|c|c|c|}
\hline Ref & Size $\left(\mathrm{mm}^{3}\right)$ & $\begin{array}{c}\text { Number of } \\
\text { Switches }\end{array}$ & $\mathrm{f}_{\mathrm{c}}(\mathrm{GHz})$ & $\begin{array}{c}\text { BW } \\
\text { (MHz) }\end{array}$ & $\begin{array}{c}\text { FBW } \\
(\%)\end{array}$ & Polarization \\
\hline [8] & $60 \times 40 \times 1.6$ & 4 & 8.4 & 700 & 8.3 & Linear \\
\hline [10] & $30 \times 40 \times 0.44$ & 2 & 2.75 & 2500 & 90.9 & Linear \\
\hline [12] & $19 \times 19 \times 1.6$ & 2 & 2.42 & 95 & 3.92 & Horizontal Vertical \\
\hline \multirow{2}{*}{ [14] } & \multirow{2}{*}{$72 \times 72 \times 12.5$} & \multirow{2}{*}{4} & 3.635 & 790 & 21.7 & \\
\hline & & & 5.11 & 1320 & 25 & Horizontal Vertical \\
\hline \multirow{2}{*}{ [15] } & \multirow{2}{*}{$40 \times 40 \times 3.175$} & \multirow{2}{*}{2} & 5.9 & 360 & 6.1 & LP \\
\hline & & & 5.95 & 700 & 11.7 & $\mathrm{CP}$ \\
\hline [16] & $\begin{array}{c}120.26 \times \\
120.26 \times 3.175\end{array}$ & 24 & 2.32 & 460 & 19.8 & RHCP LHCP \\
\hline \multirow{3}{*}{ [17] } & \multirow{3}{*}{$50 \times 50 \times 3.048$} & \multirow{3}{*}{-} & 2.4417 & 44.5 & 1.82 & Horizontal \\
\hline & & & 2.4093 & 40.5 & 1.68 & Vertical \\
\hline & & & 2.4245 & 10 & 0.41 & $\begin{array}{c}\text { RHCP LHCP } \\
\text { Diagonal }\end{array}$ \\
\hline $\begin{array}{l}\text { Proposed } \\
\text { antenna }\end{array}$ & $50 \times 50 \times 3.048$ & 2 & 2.4386 & 215.2 & 8.82 & $\begin{array}{c}\text { Horizontal Vertical } \\
\text { RHCP LHCP } \\
\text { Elliptical }\end{array}$ \\
\hline
\end{tabular}




\section{Conclusions}

In this paper an elliptical supershape patch radiator is presented. The initial Supershape patch had two resonant frequencies with fractal BW of $1.48 \%$, and $1.11 \%$, respectively. By implementing the proper feeding network, we over doubled the fractal BW of each resonance and by bridging the gap between them a wider single operation band was achieved reaching an $8.8 \%$ fractal BW. Also, by using two PIN diodes, one on each feed, the operating bandwidth can be changed, thus creating a frequency reconfigurable antenna. Finally, by using different values for the amplitude and phase of each port, all kinds of polarization can be excited.

Author Contributions: Conceptualization, G.K. and M.C.; methodology, A.K.; software, A.K. and G.X.; validation, A.K. and G.X.; formal analysis, G.K. and M.C.; investigation, A.K.; resources, A.K.; data curation, A.K.; writing —original draft preparation, A.K.; writing—review and editing, A.K. and M.C.; visualization, A.K. and M.C. All authors have read and agreed to the published version of the manuscript.

Funding: This project has received funding from the Hellenic Foundation for Research and Innovation (HFRI) and the General Secretariat for Research and Technology (GSRT), under grant agreement No [2047].

Acknowledgments: The proper matching of the antenna from $Z_{\mathrm{in} 2}=130 \mathrm{Ohm}$ to $50 \mathrm{Ohm}$ as proposed in Section 2 and carried out in Section 4 have been simulated using Optenni Lab.

Conflicts of Interest: The authors declare no conflict of interest.

\section{References}

1. Ojaroudi Parchin, N.; Jahanbakhsh Basherlou, H.; Al-Yasir, Y.I.A.; Abd-Alhameed, R.A.; Abdulkhaleq, A.M.; Noras, J.M. Recent Developments of Reconfigurable Antennas for Current and Future Wireless Communication Systems. Electronics 2019, 8, 128. [CrossRef]

2. Row, J.; Tsai, C. Pattern Reconfigurable Antenna Array with Circular Polarization. IEEE Trans. Antennas Propag. 2016, 64, 1525-1530. [CrossRef]

3. Bouslama, M.; Traii, M.; Denidni, A.T.; Gharsallah, A. Beam-Switching Antenna with a New Reconfigurable Frequency Selective Surface. IEEE Antennas Wirel. Propag. Lett. 2016, 15, 1159-1162. [CrossRef]

4. Jin, P.G.; Li, M.; Wang, W.; Li, L.; Liao, S. Planar beam-switching dipole antenna. IET Microw. Antennas Propag. 2019, 13, 997-1002. [CrossRef]

5. Jin, G.; Li, M.; Liu, D.; Zeng, G. A Simple Planar Pattern-Reconfigurable Antenna Based on Arc Dipoles. IEEE Antennas Wirel. Propag. Lett. 2018, 17, 1664-1668. [CrossRef]

6. Qin, P.; Wei, F.; Guo, J.Y. A Wideband-to-Narrowband Tunable Antenna Using A Reconfigurable Filter. IEEE Trans. Antennas Propag. 2015, 63, 2282-2285. [CrossRef]

7. Nguyen-Trong, N.; Piotrowski, A.; Hall, L.; Fumeaux, C. A Frequency- and Polarization-Reconfigurable Circular Cavity Antenna. IEEE Antennas Wirel. Propag. Lett. 2017, 16, 999-1002. [CrossRef]

8. Khan, T.; Rahman, M.; Akram, A.; Amin, Y.; Tenhunen, H. A Low-Cost CPW-Fed Multiband Frequency Reconfigurable Antenna for Wireless Applications. Electronics 2019, 8, 900. [CrossRef]

9. Li, T.; Zhai, H.; Wang, X.; Li, L.; Liang, C. Frequency-Reconfigurable Bow-Tie Antenna for Bluetooth, WiMAX, and WLAN Applications. IEEE Antennas Wirel. Propag. Lett. 2015, 14, 171-174. [CrossRef]

10. Abutarboush, F.H.; Atif Shamim, A. A Reconfigurable Inkjet-Printed Antenna on Paper Substrate for Wireless Applications. IEEE Antennas Wirel. Propag. Lett. 2018, 17, 1648-1651. [CrossRef]

11. Mathur, R.; Dwari, S. Compact planar reconfigurable UWB-MIMO antenna with on-demand worldwide interoperability for microwave access/wireless local area network rejection. IET Microw. Antennas Propag. 2019, 13, 1684-1689. [CrossRef]

12. Raman, S.; Mohanan, P.; Timmons, N.; Morrison, J. Microstrip-Fed Pattern- and Polarization- Reconfigurable Compact Truncated Monopole Antenna. IEEE Antennas Wirel. Propag. Lett. 2013, 12, 710-713. [CrossRef]

13. Shirazi, M.; Li, T.; Huang, J.; Gong, X. A Reconfigurable Dual-Polarization Slot-Ring antenna Element With Wide Bandwidth for Array Applications. IEEE Trans. Antennas Propag. 2018, 66, 5943-5964. [CrossRef]

14. Nie, Z.; Zhai, H.; Liu, L.; Li, J.; Hu, D.; Shi, J. A Dual-Polarized Frequency-Reconfigurable Low-Profile Antenna with Harmonic Suppression for 5G Application. IEEE Antennas Wirel. Propag. Lett. 2019, 18, 1228-1232. [CrossRef] 
15. Qin, P.; Weily, R.A.; Jay, Y. Polarization Reconfigurable U-Slot Patch Antenna. IEEE Trans. Antennas Propag. 2010, 58, 3383-3388. [CrossRef]

16. Cai, Y.; Gao, S.; Yin, Y.; Li, W.; Luo, Q. Compact-Size Low-Profile Wideband Circularly Polarized Omni-directional Patch Antenna with Reconfigurable Polarizations. IEEE Trans. Antennas Propag. 2016, 64, 2016-2021. [CrossRef]

17. Koutinos, G.A.; Ioannopoulos, A.G.; Chryssomallis, T.M.; Kyriacou, A.G. A Wideband Matching Technique for Polarization Versatile Applications. In Proceedings of the 36th PIERS Proceedings, Prague, Czech Republic, 6-9 July 2015; pp. 2081-2085.

18. Paraforou, V.; Tran, D.; Caratelli, D. A novel supershaped slot-loaded printed dipole antenna with broadside radiation for dual-band WLAN applications. In Proceedings of the the 8th European Conference on Antennas and Propagation (EuCAP 2014), The Hague, The Netherlands, 6-11 April 2014; IEEE: Piscataway, NJ, USA, 2014.

19. Gielis, J. A Generic geometric transformation that unifies a wide range of natural and abstract shapes. Am. J. Bot. 2003, 90, 333-338. [CrossRef] [PubMed]

20. Koutinos, G.A.; Kyriacou, A.G.; Volakis, L.G.; Chryssomallis, T.M. Bandwidth Enhancement of Antennas Designed by Band-Pass Filter Synthesis Due to Frequency Pulling Techniques. In Antennas and Propagation; IET: Stevenage, UK, under Review.

21. Rahola, J. Antenna Matching Circuit Optimization Including Stop Band Definitions. In IEEE International Symposium on Antennas and Propagation (APSURSI), 3-8 July 2011; IEEE: Spokane, WA, USA, 2011; pp. 1304-1307.

22. Pues, H.F.; Van de Capelle, A.R. An impedance-matching technique for increasing the bandwidth of microstrip antennas. IEEE Trans. Antennas Propag. 1989, 37, 1345-1354. [CrossRef]

23. Optenni Lab Antenna Analysis Software. Available online: www.optenni.com (accessed on 10 March 2020).

(C) 2020 by the authors. Licensee MDPI, Basel, Switzerland. This article is an open access article distributed under the terms and conditions of the Creative Commons Attribution (CC BY) license (http://creativecommons.org/licenses/by/4.0/). 